\title{
Degree of Czech R/L acquisition in L1 Chinese speakers
}

\author{
Petra Poukarová ${ }^{1}$, Jitka Veroňková ${ }^{2}$ \\ ${ }^{1}$ Institute of the Czech National Corpus, Charles University, Czech Republic \\ Institute of Phonetics, Charles University, Czech Republic \\ https://doi.org/10.36505/ExLing-2020/11/0040/000455
}

\begin{abstract}
This paper is based on the assumption that a successful acquisition of L2 is facilitated when the individual needs of particular students are taken into consideration. Our goal is to screen the perception and production of $r$ - and $l$-sounds in Chinese students of Czech as L2. The experiment, in which 8 subjects participated, is based on minimal pairs and consists of a listening test (72 items) and recording of read speech (single words and sentences containing target words, 64 items per speaker). Within the set of minimal pairs, the position and the combination of the target sounds are controlled. The procedure was also tested regarding its suitability for the systematic screening of students' skills.
\end{abstract}

Keywords: Czech as L2, Chinese as L1, 1-sound, r-sound, perception, production.

\section{Introduction}

It is well known fact that the Chinese have a problem distinguishing between $\mathrm{r}$ and 1-sounds when learning L2, including Czech, whose phonological system contains the alveolar trill $/ \mathrm{r} /$ and the alveolar lateral approximant $/ 1 /$. These segments formminimal pairs and their incorrect pronunciation can cause problems in the intelligibility of spoken communication. We work with the assumption that mastering the production of sound phenomena should be supported by practicing perception (Strange \& Shafer 2008), and that effective pronunciation training is based on the knowledge of the particular students' needs (Derwing and Munro 2015).

This paper describes the procedure used to screen the perception and production of Czech $\mathrm{r}$ - and l-sounds in Chinese students at the beginning of the phonetics course. The main goal was to obtain information about individual students and test whether the procedure would be suitable for a systematic use.

\section{Methodology}

8 speakers ( 7 females, 1 male) with Chinese as L1 participated in the experiments. They were students of a bachelor's degree of Czech Studies for Foreigners (Charles University, Prague) who had stayed in the Czech Republic for 3-4 months. Their level of Czech acquisition corresponded to B1-B2 of CEFR.

ExLing 2020: Proceedings of 11 th International Conference of Experimental Linguistics, 12-14 October 2020, Athens, Greece 


\section{Experiment 1 - perception test}

We formed a set of minimal pairs, which differed only in the target consonant $r$ (R) and $l(\mathrm{~L})$. The following four positions were distinguished: (1) initial before vowel CV-, (2) intervocalic VCV, (3) final -VC and (4) two-consonantal cluster CC. Each position was represented by 3 pairs, i.e., 12 minimal pairs were at our disposal. The complete set was recorded by 3 native Czech females with precise pronunciation. The recordings served as the basis for a perception test designed using Praat multiple forced-choice environment (Boersma \& Weenink 2019). The test contained 72 items altogether (i.e., 12 pairs $\times 3$ speakers) randomly ordered; 5 more items were used in the training part. The subjects' task was to indicate which sound (R or L) they hear. The test was conducted individually or in a small group, the listeners used headphones.

\section{Experiment 2 - production}

The same set as in the Experiment 1 extended by 4 more CC pairs to make a record was used. First, subjects read the sentences, each of which contained one target word in the middle (32 sentences, 1 page). They were provided a little time to read the sentences in advance. Afterwards they read the whole set again as individual words (randomly ordered), without preparation. Recordings were taken individually in a sound-treated room (AKG C 4500 B$\mathrm{BC}$ microphone, sample rate $48 \mathrm{kHz}, 16$-bit depth).

We calculated the number of correct answers (Experiment 1) and performed a perceptual analysis of the pronunciation of the target sounds R/L (Experiment 2). For perceptual analysis, we applied both a phonological view and monitored the phonetic quality.

\section{Results}

\section{Experiment 1 - perception test}

The ratio of incorrect items was $12 \%$ in both $\mathrm{R}$ and $\mathrm{L}$, however, perception of each phoneme proved to cause difficulties in different patterns.

In the case of R, errors occurred predominantly in VCV. For example, the error rate for the lexeme viry (Eng. viruses), tested in 3 items, is 9 of 24 judgements, and for the lexeme póry (Eng. pores) 6/24. Compared to that, in the case of L, CC and CV-covered most of the errors. For example, the lexeme blany (Eng. membranes) showed an error rate 6/24, and the lexeme luka (Eng. meadows) $7 / 24$.

The proportion of errors varied considerably between subjects: for 5 subjects, perception was easy, they had only up to $5 \%$ errors; 1 subject showed error rate of $12.5 \%$; for 2 subjects, the task to discriminate $r$ - and $l$ sound was difficult (error rate 30.6\% and 38.9\%). 


\section{Experiment 2 - production}

511 of target items were analysed (255 within sentences - with 1 sample excluded because of a technical error, 256 single words).

$71.2 \%$ of target items were pronounced with correct phonemes. Speakers were more successful in pronouncing the consonant $\mathrm{L}(83.9 \%)$ than the consonant $\mathrm{R}(58.6 \%)$. In this respect, the $-\mathrm{VC}$ position is specific: the number of correct Rs is higher than the number of correct Ls; the L items are often pronounced as labial approximants in this position.

In $16.8 \%$ of items, the original sound was substituted by the $\mathrm{R} / \mathrm{L}$ counterpart. Substitution of $\mathrm{R}$ by $\mathrm{L}$ occurred with considerably higher frequency than, conversely, L by R $(87.2 \%$ vs. $12.8 \%)$, for example valu (Eng. earthwork, Gen. sg) instead of varu (Eng. boil, Gen. sg) or dluby (Eng. debts) instead of druby (Eng. kinds). In one case, the speaker pronounced trill fricative $/ \mathrm{r} /$ instead of $/ \mathrm{r} /$.

Relatively often, in $11.7 \%$ of cases, realization was not intelligible enough to classify the sound as R or L unmistakably, mainly due to glottalization at the end of the word.

In general, success in production is similar regardless of whether the target items are tested as individual words or in the carrier sentence (see Table 1). The differences may be clearly observed once the specific positions have been compared. For example, the increase of the $\mathrm{L}$ to $\mathrm{R}$ substitutions in the CVposition in the sentences compared to the single words is apparent. The proportion of correctly pronounced Rs rises in VCV in the case of single words.

Table 1. Success rate of pronunciation $r$ - and 1 -sounds (R, L) in single words and in the middle of a sentence. The table shows the rate score of phonologically correct pronunciation, the number of realizations the sound was substituted by the R/L counterpart, or could not be unambiguously classified.

\begin{tabular}{|l|l|l|l|l|l|l|}
\hline & \multicolumn{3}{|c|}{ Words $(\mathrm{N}=256)$} & \multicolumn{3}{l|}{ Sentences (N=255) } \\
\hline$\%$ & L & $\mathrm{R}$ & Sum & L & $\mathrm{R}$ & Sum \\
\hline Correct pronun. & 41.0 & 30.5 & 71.5 & 42.7 & 28.2 & 71.0 \\
\hline Substitution R/L & 13.7 & 1.6 & 15.2 & 15.7 & 2.7 & 18.4 \\
\hline Not clear & & & 13.3 & & & 10.2 \\
\hline Other & & & & & & 0.4 \\
\hline & & & 100.0 & & & 100.0 \\
\hline
\end{tabular}

Regarding the subjects, there are distinct differences in the success rate (from $38 \%$ to $95 \%$ of correctly pronounced items). The three subjects with the lowest success in perception are among the four speakers with the lowest scores in production (the success rate up to $50.0 \%$ ). On the other hand, the pronunciation of the three subjects was more than $90 \%$ successful. It is 
possible to trace individual tendencies, concerning, for example, phonetic realization and positions.

\section{Conclusion}

The procedure proved to be feasible as it provides data on the perception and production of individual students. For both kinds of skill, it is useful to examine different positions of the target segments. The production of words as both single items and constituents of sentences can also display differences, so it is desirable to keep both types of text. The design of the listening test has also proved successful and its adaptation can be used to practice perception. The information obtained can contribute not only to the subsequent creation or selection of appropriate exercises, but also to a better understanding of the process of acquisition of the Czech sound patterns in Chinese speakers.

\section{Acknowledgments}

This research was supported by the Czech Science Foundation project No. 18-18300S "Phonetic properties of Czech in non-native and native speakers' communication". We would like to thank Tomáš Bořil (Institute of Phonetics, Charles University, Prague) for designing the perception test.

\section{References}

Boersma, P., Weenink, D. 2019. Praat: doing phonetics by computer [Computer program], version 6.0.25.

Common European Framework of Reference for Languages: Learning, teaching, assessment (CEFR), https:/ /www.coe.int/en/web/common-european-frameworkreference-languages.

Derwing, T. M., Munro, M. J. 2015. Pronunciation Fundamentals. Evidence-based Perspectives for L2 Teaching and Research. Amsterodam / Philadelphia, John Benjamins Publishing Company.

Strange, W., Shafer, V. L. 2008. Speech perception in second language learners: The reeducation of selective perception. In Edwards, J. G. H., Zampini, M. L. (eds.), Phonology and Second Language Acquisition, 153-191. Amsterodam / Philadelphia, John Benjamins Publishing Company. 